\title{
Influence of GCSF stimulation on sCD40L release kinetic
}

\author{
Folker Wenzel $^{\mathrm{a}, *}$, Maximilian Hauser ${ }^{\mathrm{b}}$, Johannes Fischer ${ }^{\mathrm{b}}$, Rainer Haas ${ }^{\mathrm{c}}$ \\ and Bernhard H. Rauch ${ }^{\mathrm{d}}$ \\ ${ }^{a}$ Hochschule Furtwangen University, Villingen-Schwenningen, Germany \\ ${ }^{\mathrm{b}}$ Institute for Transplantation Diagnostics and Cell Therapeutics, Heinrich-Heine-University, \\ Düsseldorf, Germany \\ ${ }^{\mathrm{c} D e p a r t m e n t}$ of Hematology, Oncology and Clinical Immunology, Heinrich-Heine-University, \\ Düsseldorf, Germany \\ ${ }^{\mathrm{d}}$ Institut für Pharmakologie, Center of Drug Absorption and Transport, Universitätsmedizin \\ Greifswald, Ernst-Moritz-Arndt Universität, Greifswald, Germany
}

\begin{abstract}
.
INTRODUCTION: It has been demonstrated by in vitro experiments using inhibitors that CD40L is cleaved from the surface of activated platelets by matrix-metalloproteinases (MMP). Additionally, after granulocyte colony stimulating factor (GCSF) activation of peripheral stem cell donors a MMP elevation is induced, and stem cell products contain a considerable amount of platelets. Therefore stem cell donations (peripheral stem cell apheresis (PBSC) as well as bone marrow (BM) donation) were used as an in vivo model to observe alterations of the sCD40L release kinetic and its effects on the respective stem cell products.

MATERIAL AND METHODS: The study included twelve healthy stem cell donors (PBSC $n=6, \mathrm{BM} n=6)$. sCD40L concentrations, relative MMP activities and blood cell compositions were determined in peripheral blood as well as in the respective stem cell products before, during and after donation and/or during cell product storage.

RESULTS: In stem cell products, sCD40L concentrations were manifold elevated (range from 1121 to $4123 \mathrm{pg} / \mathrm{mL}$ ) in comparison to concentrations of peripheral blood samples (range from 39 to $334 \mathrm{pg} / \mathrm{mL}$ ). Dependent on storage duration a sCD40L accumulation in the products could be observed. MMP concentrations were elevated by GCSF stimulation and resulted in an about 2-fold increase of sCD40L release kinetic. In parallel, MMP concentrations were increased in the stem cell products (PBSC as well as BM products). In the peripheral blood of PBSC donors, the sCD40L concentration decreased after apheresis in correlation to a decrease in platelet count.

CONCLUSION: As known from platelet concentrates, an accumulation of sCD40L could also be observed in stem cell products pointing out the importance of sCD40L release by platelets. Stem cell products showed elevated MMP concentrations compared to peripheral blood and additionally during stem cell apheresis, sCD40L release kinetic is accelerated by MMP elevation.
\end{abstract}

\section{Introduction}

Soluble CD40L (sCD40L) is a member of the tumor necrosis family and well known to be a cytokine acting as a potent immune modulator. SCD40L can lead to B-cell immunoglobulin class switching under maturation of dendritic cells, by interaction with its receptor CD40 [8]. Beside the well studied immunological phenomena, sCD40L seems to have effects on platelets and various non hematopoietic

\footnotetext{
*Corresponding author: Folker Wenzel, Hochschule Furtwangen University, Villingen-Schwenningen, Germany. E-mail: wfo@hs-furtwangen.de.
} 
cells. So the expression of CD40 and CD40L is not restricted to cells of the immune system. It is known that smooth muscle cells, fibroblasts, keratinocytes and thrombocytes also using CD40/CD40L signalling $[8,12]$. It is assumed that $\mathrm{SCD} 40 \mathrm{~L}$ influences the stability of arterial thrombi and the development of arterial occlusion [2]. sCD40L acting as an inflammatory mediator plays a role in inflammatory diseases such as atherosclerosis, not only by binding to its classical receptor CD40, but also interacting with Mac-1, expressed abundantly on monocytes and macrophages [20]. In addition sCD40L may support coagulation by inducing TF expression on monocytes [2].

Platelets are assumed to be the major source for SCD40L in the peripheral blood $[1,16]$. It has been demonstrated by in vitro experiments using inhibitors that CD40L is cleaved from the surface of activated platelets by matrix-metalloproteinases (MMP) $[5,15]$. These effects cause the observed phenomenon of sCD40L accumulation in stored platelet concentrates [3, 8, 17].

Additionally, after granulocyte colony stimulating factor (GCSF) activation of peripheral stem cell donors a MMP elevation is induced, and stem cell products contain a considerable amount of platelets. Overall, considering these theoretical and clinical findings it can be expected that there is an influence of GCSF administration on sCD40L release in the context of stem cell donation. Therefore stem cell donations (peripheral stem cell apheresis (PBSC) as well as bone marrow (BM) donation) were used as an in vivo model to observe these alterations and its effects on the respective stem cell products.

\section{Material and methods}

\subsection{Donors characteristics}

The study included twelve healthy stem cell donors ( 5 women, 7 men, mean age $42.1 \pm 12.3$ years (range 24 to 58 years), $\operatorname{PBSC} n=6, \mathrm{BM} n=6$ ). Blood samples were taken before and after SC donation. sCD40L levels in plasma samples of peripheral blood and of the respective blood products, as well as platelet count, were determined. Additionally, relative MMP concentrations were determined by respective zymograms.

Written informed consent was obtained from each donor before entry into the study, and the study protocol conformed to the ethical guidelines of the 1975 Declaration of Helsinki as reflected in a priori approval by the appropriate institutional review committee.

\subsection{Stem cell products}

PBSC products were collected by peripheral stem cell apheresis using a semi-automated haemapheresis procedure (Cobe Spectra, Terumo BCT, USA). BM products were collected by respective puncturing and harvesting a BM volume up to $20 \mathrm{ml} / \mathrm{kg} \mathrm{BW}$ of the donor. All donors met the national criteria. Before apheresis, a GCSF stimulation was performed (GCSF $10 \mu \mathrm{g} / \mathrm{kg} \mathrm{BW}$ for five days) to elevate the stem cell concentration in the peripheral blood.

To determine sCD40L concentrations in the plasma of the stem cell products immediately after donation and after $24 \mathrm{~h}$ storage $10 \mathrm{ml}$ of each product were filled under sterile conditions in an additional mini bag appendent to the original product system and consisting of the same material as the product bag.

\subsection{Enzyme-linked immunosorbent assay for $s C D 4 O L$}

sCD40L concentrations were determined in stored blood samples (stored at $-70^{\circ} \mathrm{C}$ ) by a commercially available ELISA kit (QuantikineTM Human sCD40L Immunoassay, R\&D Systems, 
Minneapolis, U.S.A.) using 3,3'5,5'-tetramethylbenzidine as a substrate for horseradish peroxidase. The sCD40L concentration was calculated by comparing the absorbance rates of the probes determined at $450 \mathrm{~nm}$ with a corresponding standard curve. The optical density of each well was determined by a microtiter plate reader (SLT-Labinstruments, Overath, Germany).

Platelet counts were obtained by an automated haematology analyzer (XE-2100, Sysmex Corporation, Japan).

All determinations were performed in duplicate.

\subsection{Zymography}

Zymography was performed on 7\% SDS/polyacrylamide gels (SDS-PAGE), containing $0.7 \mathrm{mg} / \mathrm{mL}$ gelatin as previously described [14]. In brief, serum samples from peripheral blood or stem cell preparations were resolved in nonreducing Laemmli-buffer (2\% wt/vol SDS, $10 \%$ glycerol, $0.0625 \mathrm{~mol} / \mathrm{L}$ sodium dihydrogen phosphate/disodium hydrogen phosphate, $\mathrm{pH} 7.0$, and $0.01 \%$ bromophenol blue). To obtain optimal protein resolution, serial sample dilutions of 1:16, 1:32, and 1:64 in Laemmli-buffer were performed. Samples were separated by electrophoresis. Gels were washed 3 times for $10 \mathrm{~min}-$ utes at room temperature in washing buffer $(50 \mathrm{mmol} / \mathrm{L}$ Tris- $\mathrm{HCl}, \mathrm{pH} 7.5,10 \mathrm{mmol} / \mathrm{L} \mathrm{CaCl} 2,1 \mathrm{~mol} / \mathrm{L}$ $\mathrm{ZnCl} 2,2.5 \%$ Triton $\mathrm{X}-100,0.02 \% \mathrm{NaN} 3$ ) to remove SDS from the gels. Gels were incubated in washing buffer containing $1 \%$ Triton $\mathrm{X}-100$ for 18 hours at $37^{\circ} \mathrm{C}$. Gels were stained with Coomassie Brilliant Blue R-250 (0.2\%) in 40\% methanol and 10\% acetic acid. Intensity of MMP-2 and MMP-9 bands was quantified on a Gel Doc 1000 with Quantity One software (Bio-Rad) as described [14].

\subsection{Statistical analysis}

Results are expressed as mean value \pm standard error of the mean (SEM). To test for significance of differences between the mean values of the controls vs. the mean values of treated groups, the unpaired Mann-Whitney-test was used. A $p$ value $<0.05$ was considered to be significant.

\section{Results}

\subsection{Cell counts}

The PBSC stem cell products showed $9.7 \pm 4.3 \times 10^{\wedge} 10 \mathrm{MNC}(31.8 \pm 12.4 \%$ granulocytes $)$, $6.5 \pm 3.8 \times 10^{\wedge} 8 \mathrm{CD} 34+$-cells, $4.0 \pm 0.9 \times 10^{\wedge} 11$ platelets in $279 \pm 112 \mathrm{ml}$. The BM stem cell products showed $1.9 \pm 0.7 \times 10^{\wedge} 10 \mathrm{MNC}, 3.7 \pm 1.3 \times 10^{\wedge} 8 \mathrm{CD} 34+$-cells, $0.5 \pm 0.3 \times 10^{\wedge} 11$ platelets in $1076 \pm 356 \mathrm{ml}$.

\subsection{Matrix-Metallo-Proteinases (MMP)}

After GCSF-stimulation in preparation for peripheral stem cell apheresis an increase in MMP-9- and MMP-2-concentrations of the peripheral blood could be observed (Fig. 1). In addition, the sCD40L release kinetic per minute in the respective whole blood and PRP samples (comparison between MMP activities before and after GCSF stimulation) was elevated about 2-fold (Fig. 2).

After stem cell donation, there was also in parallel to the MNC accumulation a significant increase in MMP-9- and MMP-2-concentrations of the plasma in PBSC as well as BM products (Fig. 3). 


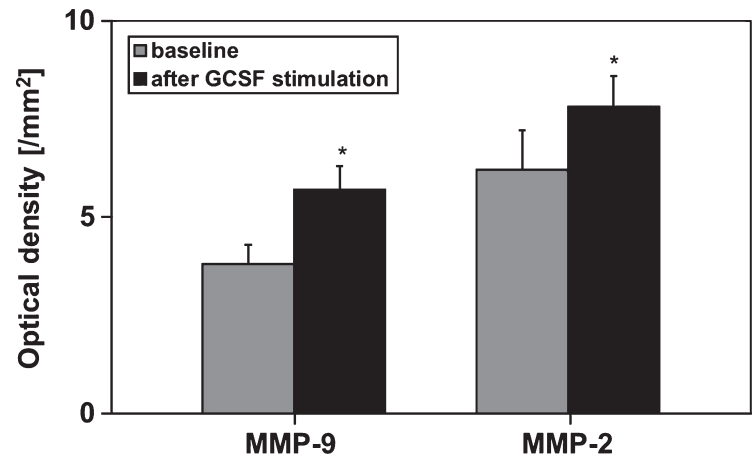

Fig. 1. Semiquantitative analysis of MMP-2- and MMP-9-concentrations by determing the optical densities of respective zymograms using peripheral blood of allogenic stem cell donors $(n=6)$ before and after GM-GCSF-stimulation $(5 \mathrm{~d}, 10 \mu \mathrm{g} / \mathrm{kg}$ $\mathrm{BW})$. Data are given as mean $\pm \mathrm{SEM},{ }^{*} p<0,05$ compared to baseline, Mann-Whitney-Test.

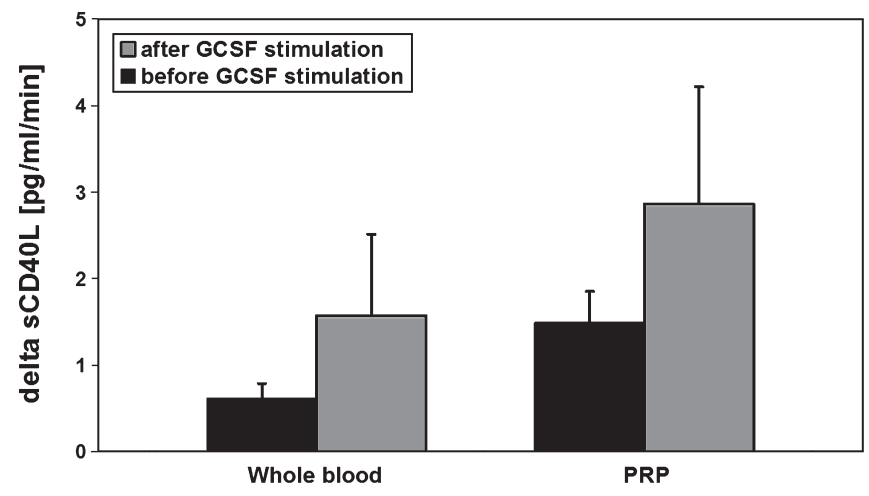

Fig. 2. sCD40L release kinetic determined from whole blood and platelet rich plasma (PRP) of healthy allogenic PBSC donors $(n=6)$ before and after GCSF stimulation $(5 \mathrm{~d}, 10 \mu \mathrm{g} / \mathrm{kg} \mathrm{BW})$. The blood samples were incubated for $60 \mathrm{~min}$ at $37^{\circ} \mathrm{C}$. Data are given as mean value $\pm \mathrm{SEM},{ }^{*} p<0,05$, Mann-Whitney-Test.

\section{3. sCD40L concentrations}

In peripheral blood of PBSC donors and BM donors plasma sCD40L levels were in a range between $15-340 \mathrm{pg} / \mathrm{mL}$ (PBSC $127 \pm 84 \mathrm{pg} / \mathrm{mL}, \mathrm{BM} 102 \pm 71 \mathrm{pg} / \mathrm{mL}$ ). There was no significant difference between the PBSC and BM donors.

In PBSC donors, a platelet loss was accompanied by a significant lowering of SCD40L concentrations in peripheral blood samples ( $p<0.05$, Student's t-test, correlation coefficient $r=0.9$ corresponding to the platelet count) (Fig. 4).

In apheresis stem cell units, the platelet count showed normally pathophysiological levels and ranged from about $900 / \mathrm{nL}$ up to $3000 / \mathrm{nL}$. In parallel, sCD40L concentrations were elevated substantially above peripheral blood levels to a range from about $400 \mathrm{pg} / \mathrm{mL}$ up to $1,200 \mathrm{pg} / \mathrm{mL}(670 \pm 137 \mathrm{pg} / \mathrm{mL})$. The sCD40L concentrations were elevated substantially above peripheral blood levels $(p<0.05$ compared to peripheral blood).

In stem cell units collected from bone marrow, the sCD40L concentrations reached also a pathophysiological range from about $600 \mathrm{pg} / \mathrm{mL}$ up to $1600 \mathrm{pg} / \mathrm{mL}(983 \pm 421 \mathrm{pg} / \mathrm{mL})$ in comparison to the peripheral blood. The platelet count in the bone marrow showed a reduced range from $80 / \mathrm{nL}$ to 160/nL. 


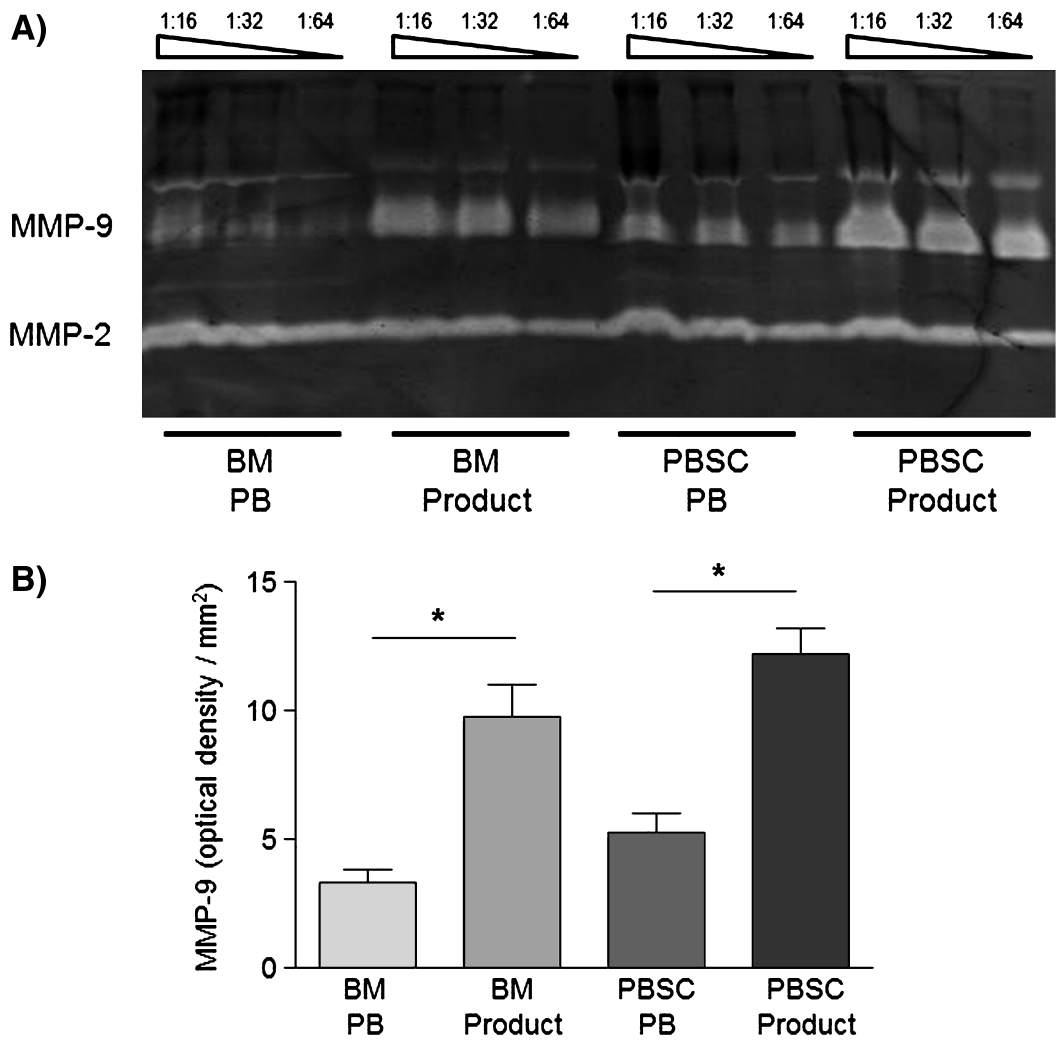

Fig. 3. A) Zymogram of the peripheral blood (PB) and the respective SC product of a single BM and a single PBSC donor showing bands for MMP-2- and MMP-9-proteins and B) respective semiquantitative analysis of MMP-9-concentrations of $\mathrm{PB}$ and product plasma in $\mathrm{BM}(n=6)$ and $\mathrm{PBSC}(n=6)$ donors by determing the optical densities of the respective zymograms. Data are given as mean $\pm \mathrm{SEM},{ }^{*} p<0,05$ compared to baseline, Mann-Whitney-Test.

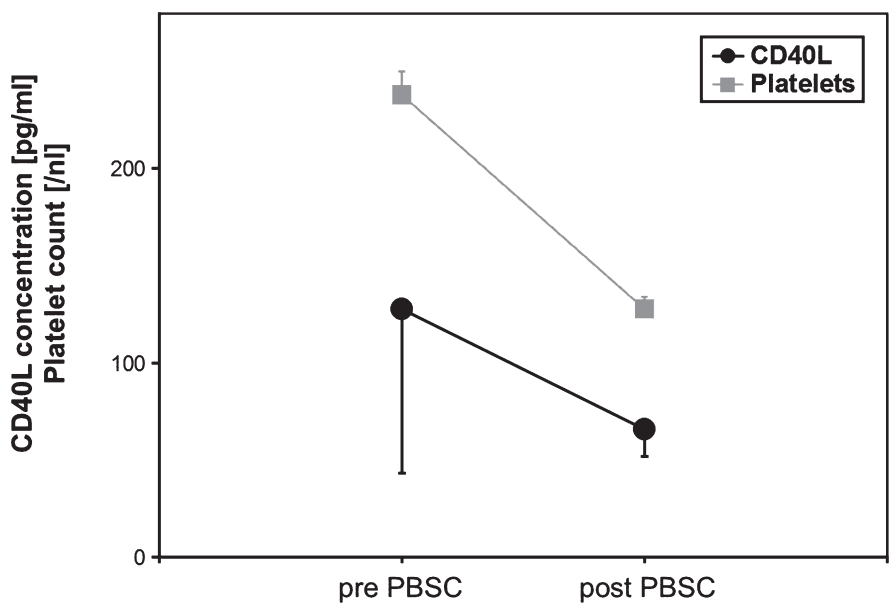

Fig. 4. Platelet count and sCD40L concentrations in peripheral blood from allogenic PBSC donors $(n=6)$ during stem cell apheresis. Data are given as mean $\pm \mathrm{SEM}$. 


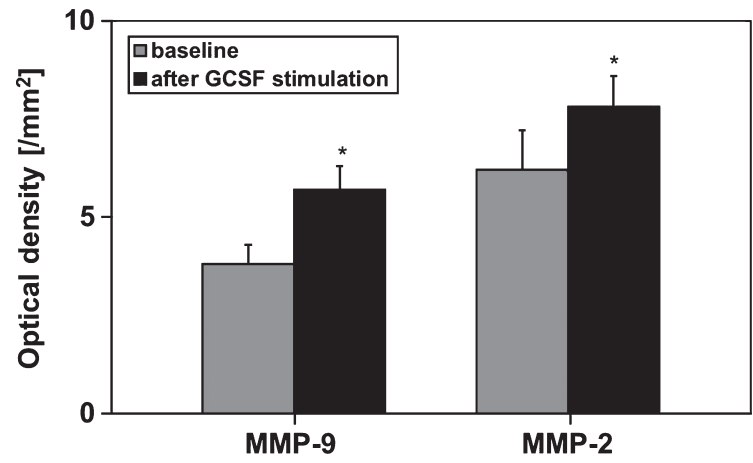

Fig. 5. Soluble CD40 Ligand (sCD40L) concentrations of respective PBSC units immediately and after $24 \mathrm{~h}$ of storage $(n=6)$. Data are given as mean \pm SEM, ${ }^{*} p<0,05$, Mann-Whitney-Test.

After $24 \mathrm{~h}$ storage, PBSC as well as BM SC products showed an accumulation of sCD40L (PBSC $2098 \pm 563$ pg/mL, BM $1554 \pm 817$ pg/mL) (Fig. 5).

\section{Discussion}

In this study it could be observed that SCD40L reached substantial levels in stem cell products resulting in a $\mathrm{SCD} 40 \mathrm{~L}$ accumulation during product storage. This phenomenon is supported by increased MMP concentrations caused either by predonational GCSF stimulation in the peripheral blood or leukocyte enrichment in the platelet-rich SC products. In addition, sCD40L expression in plasma samples of peripheral blood was dependent on platelet count.

In the literature, for plasma sCD40L of the peripheral blood a range between $40-240 \mathrm{pg} / \mathrm{mL}$ (Chew, et al.), [16] is described. These levels could also be found in the examined allogenic stem cell donors.

In contrast, in stem cell products we could observe pathophysiological sCD40L levels. These observations are in line with the observations on SCD40L release in platelet concentrates $[17,18]$. In support Woods et al. [19] described a SCD40L increase after a 48 hour storage period in products obtained by peripheral stem cell apheresis of allogenic donors.

Due to the descriptions by Domanovic et al. and Klein et al. that GCSF administration resulted in MMP activation [6, 10] we could observe in the PBSC donors after GCSF stimulation an increase in MMP concentrations. These descriptive data could be confirmed in our study by functional data showing also an elevated sCD40L release kinetic. Additionally, it is known that MMP activities are triggered by leukocytes $[7,11]$. In line with these expectations we found elevated MMP concentrations in the leukocyte enriched SC products. These sCD40L alterations are in line with the sCD40L accumulation during the storage period, especially in cause of the high platelet contain of stem cell products.

At least Khan et al. and Phipps et al. [9, 13] demonstrated in an experimental work that sCD40L levels could be indirectly involved in the development of adverse transfusion reactions. But due to a lack of sufficient data regarding the pathophysiological sCD40L levels in the stem cell products under clinical routine use one may currently only speculate on effects of sCD40L influencing directly the haematopoietic stem cells in the product itself or triggering adverse transfusion reactions.

These theoretical and clinical findings show that there is a sCD40L accumulation in stem cell products triggered by elevated MMP activities. However, the pathophysiological meaning is based only on speculative considerations. But these may help to initiate respective experimental and clinical studies. 


\section{References}

[1] Andre P, Nannizzi-Alaimo L, Prasad SK, Phillips DR. Platelet-derived CD40L: The switch-hitting player of cardiovascular disease. Circulation 2002a; 106:896-9.

[2] Andre P, Prasad KS, Denis CV, He M, Papalia JM, Hynes RO, Phillips DR, Wagner DD. CD40L stabilizes arterial thrombi by a beta3 integrin-dependent mechanism. Nat Med 2002b;8:247-52.

[3] Blumberg N, Gettings KF, Turner C, Heal JM, Phipps RP. An association of soluble CD40 ligand (CD154) with adverse reactions to platelet transfusions. Transfusion 2006;46:1813-21.

[4] Chew M, Rahman M, Ihrman L, Erson A, Zhang S, Thorlacius H. Soluble CD40L (CD154) is increased in patients with shock. Inflamm Res 2010;59:979-82.

[5] Choi WS, Jeon OH, Kim DS. CD40 ligand shedding is regulated by interaction between matrix metalloproteinase-2 and platelet integrin alpha(IIb)beta(3). J Thromb Haemost 2010;8:1364-71.

[6] Domanovic D, Wozniak G, Cernelc P, Samardzija M, Balen-Marunic S, Rozman P. Matrix metalloproteinase-9 and cell kinetics during the collection of peripheral blood stem cells by leukapheresis. Transfus Apher Sci 2005;33:37-45.

[7] Greenbaum AM, Link DC. Mechanisms of G-CSF-mediated hematopoietic stem and progenitor mobilization. Leukemia 2011;25:211-7.

[8] Kaufman J, Spinelli SL, Schultz E, Blumberg N, Phipps RP. Release of biologically active CD154 during collection and storage of platelet concentrates prepared for transfusion. J Thromb Haemost 2007;5:788-96.

[9] Khan SY, Kelher MR, Heal JM, Blumberg N, Boshkov LK, Phipps R, Gettings KF, McLaughlin NJ, Silliman CC. Soluble CD40 ligand accumulates in stored blood components, primes neutrophils through CD40, and is a potential cofactor in the development of transfusion-related acute lung injury. Blood 2006;108:2455-62.

[10] Klein G, Schmal O, Aicher WK. Matrix metalloproteinases in stem cell mobilization. Matrix Biology 2015;44-46:17583.

[11] Lapidot T, Petit I. Current understanding of stem cell mobilization: The roles of chemokines, proteolytic enzymes, adhesion molecules, cytokines, and stromal cells. Exp Hematol 2002;30:973-81.

[12] Mach F, Schonbeck U, Sukhova GK, Bourcier T, Bonnefoy JY, Pober JS, Libby P. Functional CD40 ligand is expressed on human vascular endothelial cells, smooth muscle cells, and macrophages: Implications for CD40-CD40 ligand signaling in atherosclerosis. Proc Natl Acad Sci U S A 1997;94:1931-6.

[13] Phipps RP, Kaufman J, Blumberg N. Platelet derived CD154 (CD40 ligand) and febrile responses to transfusion. Lancet 2001;357:2023-4.

[14] Rauch BH, Bretschneider E, Braun M, Schrör K. Factor Xa releases matrix metalloproteinase-2 (MMP-2) from human vascular smooth muscle cells and stimulates the conversion of pro-MMP-2 to MMP-2: role of MMP-2 in factor Xainduced DNA synthesis and matrix invasion. Circ Res 2002;90:1122-7.

[15] Reinboldt S, Wenzel F, Rauch BH, Hohlfeld T, Grandoch M, Fischer JW, Weber AA. Preliminary evidence for a matrix metalloproteinase-2 (MMP-2)-dependent shedding of soluble CD40 ligand (sCD40L) from activated platelets. Platelets 2009;20:441-4.

[16] Wenzel F, Baertl A, Zimmermann N, Hohlfeld T, Giers G, Oldenburg J, Assert R. Different behaviour of soluble CD40L concentrations can be reflected by variations of preanalytical conditions. Clin Hemorheol Microcirc 2008;39:417-22.

[17] Wenzel F, Gunther W, Baertl A, Lasshofer R, Rox J, Fischer JC, Giers G. Comparison of soluble CD40L concentrations and release capacities in apheresis and prestorage pooled platelet concentrates. Clin Hemorheol Microcirc 2011a;47:26978.

[18] Wenzel F, Gunther W, Rox JM, Fischer JC, Giers G. Soluble CD40 ligand in stem cell products of autologous donors. Transfusion 2011b;51:226-7.

[19] Woods I, Tawab-Amiri A, Byrne K, Sabatino M, Stroncek DF. Pilot analysis of cytokines levels in stored granulocytecolony-stimulating factor-mobilized peripheral blood stem cell concentrates. Transfusion 2010;50:2011-5.

[20] Zirlik A, Maier C, Gerdes N, MacFarlane L, Soosairajah J, Bavendiek U, Ahrens I, Ernst S, Bassler N, Missiou A, Patko Z, Aikawa M, Schonbeck U, Bode C, Libby P, Peter K. CD40 ligand mediates inflammation independently of CD40 by interaction with Mac-1. Circulation 2007;115:1571-80. 